\title{
Exploring the Spatial Variability in Soil Macronutrients (NPK) of Coconut Research Station, Aliyar Nagar employing Geospatial Techniques
}

\author{
C. Sudhalakshmi*, R. Kumaraperumal, K. Arulmozhiselvan and N. Shoba \\ Coconut Research Station, Tamil Nadu Agricultural University, Aliyar Nagar, Coimbatore (Dt) Tamil Nadu
}

\begin{abstract}
Knowledge on the soil variability of research stations is imperative for the assessment of land capability for specific land use and for the correlation of experimental data generated in various research trials. A study was undertaken in Coconut Research Station, Aliyar Nagar to characterize the spatial variability of available macronutrients (nitrogen $(\mathrm{N})$, phosphorus $(\mathrm{P})$ and potassium $(\mathrm{K})$ ) and to compute their respective nutrient indices. Two hundred and fifty eight geo - referenced soil samples were collected from the surface $(0-15 \mathrm{~cm})$ and subsurface $(15-30 \mathrm{~cm})$ layers of $A$, $B$ and $\mathrm{C}$ blocks of the farm. The farm soil is predominantly sandy textured belonging to the taxonomic class Typic / Fluventic Ustropept. $\mathrm{KMnO}_{4}-\mathrm{N}$, Olsen $\mathrm{P}$ and $1 \mathrm{NNH}_{4} \mathrm{OAc} \mathrm{K}$ were estimated adopting the standard procedures. GIS aided fertility maps were prepared employing Arc-GIS software and nutrient indices were computed. Acute deficiencies of nitrogen and moderate deficiencies of phosphorus and potassium were observed in the soils. Sandy texture of the soil, intensive irrigation systems, paucity of organic matter, low base exchange status and kaolinitic clay mineral with poor potassium binding sites are the potential causes for nutrient deficiencies. Enhancing the organic matter load through residue recycling, split application of $\mathbf{N}$ and $\mathrm{K}$ fertilizers and water saving irrigation systems can reverse the above effect.
\end{abstract}

Key words : Fertility mapping, GIS, Nutrient index, Spatial variability

Soil representing a continuum, of diversified genetic processes and being one of the biggest natural heritages of mankind deserve greater consideration than merely as medium of plant growth. Plethora of evidences has accumulated stating that soil properties vary across farm fields, causing spatial variability in crop yields (Rockstrom et al., 1999; Gaston et al., 2001). Conventional blanket use of fertilizer not only reduces nutrient use efficiency but also causes nutrient imbalances in soil resulting in decreased crop yields (Ladha et al., 2005). Soil fertility evaluation in researcher-managed plots wherein technologies emerge, requires a unified approach and the results can be successful only if the evaluation is a continuous process. There are various techniques for soil fertility evaluation, of which soil testing is the most widely accepted tool in the world (Havlin et al., 2010).

Spatially and temporally dynamic soil management practices are the important factors in successful site specific management strategy. For studies on the spatial distribution pattern of soil properties, techniques such as conventional statistics and geostatistics are widely applied (Liu et al., 2006). The advent of information technology has provided tools like Global Positioning System (GPS) and Geographical Information System (GIS) which helps in collecting a systematic set of georeferenced samples and in generating the spatial data about the distribution of nutrients (Sharma, 2004).

*Corresponding author email: soilsudha@yahoo.co.in
At Coconut Research Station, Aliyar Nagar, research on crops of varying phenology and variable nutrient demands viz., coconut, groundnut, paddy, cocoa, pepper, tomato and brinjal are in vogue. Knowledge of the native soil fertility of the farm is imperative for efficient nutrient management and for correlation of research findings generated through various research trials. Hence the study was framed with the main objective to explore, document and map the spatial variability of soil macronutrients $(N$, $\mathrm{P}$ and $\mathrm{K}$ ) in Coconut Research Station, Aliyar Nagar.

\section{Material and Methods}

Coconut Research Station, Aliyar Nagar is located in the Western Zone of Tamil Nadu at $10^{\circ} 28^{\prime} \mathrm{N}$ latitude and 76058' $\mathrm{E}$ longitude at an altitude of $288 \mathrm{~m}$. The annual precipitation of the region in which the station is located is $802 \mathrm{~mm}$. The mean maximum and minimum temperatures are $34^{\circ} \mathrm{C}$ and $24^{\circ} \mathrm{C}$ respectively. The station has a total area of 21.7 ha with a cultivable area of 18.7 ha. The soils are sandy loam to sandy clay loam in texture taxonomically classified as Typic / Fluventic Ustropept. The major and predominant geological formations of Aliyar are of granite gneiss, biotite gneiss and charnockite. The station comprises of A, B and C blocks. Georeferenced surface (0-15 $\mathrm{cm})$ and subsurface $(15-30 \mathrm{~cm})$ soil samples were collected from A (14 fields), B (17 fields) and C blocks (12 blocks) @ six samples per field in three locations L1, L2 and L3, thus totaling 258 samples (Figure 1). 


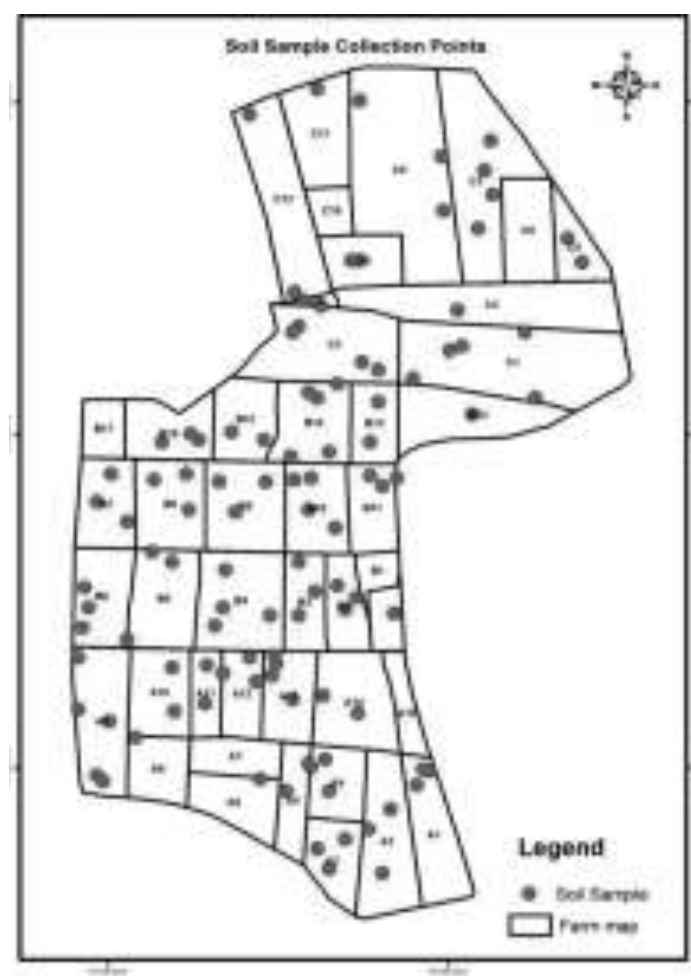

Figure 1. Soil sampling locations of Coconut Research Station, Aliyar Nagar

The $\mathrm{pH}$ of the soil samples was neutral in reaction and electrical conductivity was harmless throughout the farm. The soils are moderately calcareous with free $\mathrm{CaCO}_{3}$ of $3-15 \%$. Available nitrogen, phosphorus and potassium were estimated as per the standard procedures outlined by Subbiah and Asija (1956), Olsen et al. (1954) and Stanford and English (1949) respectively. The farm map was overlaid over Quick Bird Satellite imagery (Figure 2) and digitized. A database file consisting of data for $X$ and $Y$ coordinates was created in Microsoft excel. A shape file showing the sampling locations was created in Arc GIS software. The database file was joined to the point data. Thematic maps on available nutrient status ( $\mathrm{N}, \mathrm{P}$ and $\mathrm{K}$ ) were generated by categorizing the fertility status as 'low', 'medium' and 'high' by kriging.

Nutrient index is used to represent the soils under low, medium and high categories. Nutrient indices of the soil samples were calculated employing the following formula.

( $1 \mathrm{x}$ number of samples in low status) $+(2 \times$ number of samples in medium status $)+(3 \times$ number of samples in

Nutrient high status)

index $=$

Total number of samples

Nutrient index value of less than 1.67 is considered as low, 1.67 to 2.45 as medium and more than 2.45 as high.

\section{Results and Discussion}

$\mathrm{KMnO}_{4}-\mathrm{N}$

The available nitrogen status of the farm soils ranged from 113 to $389 \mathrm{~kg} \mathrm{ha}^{-1}$ with a mean content of $233.6 \mathrm{~kg} \mathrm{ha}^{-1}$. The general trend noticed was that the soil samples were low to medium in available nitrogen status. In the surface soil, $84 \%$ of the soil samples recorded low status and $16 \%$ of the samples recorded high status of available nitrogen. In the sub surface, about $92 \%$ of the samples had low status, $8 \%$ of the soil samples medium and not even a single sample of the 258 had recorded high status of $\mathrm{KMnO}_{4}$ - N. In the surface samples of the fields A2, A3, A4 and $A 5$, the status was medium as noted in the map, which is mainly because of in situ incorporation of groundnut haulms resulting in subsequent build up of organic matter, henceforth increasing the available nitrogen content of the soil (Figure 1).

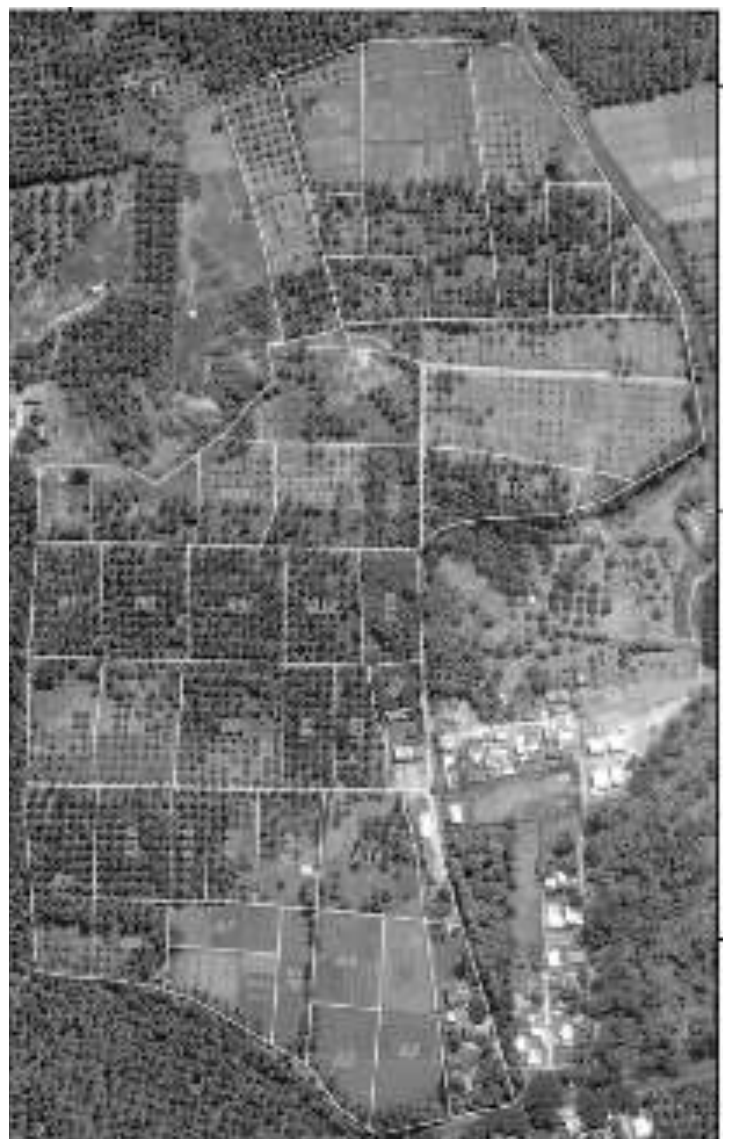

Figure 2. Farm map overlaid over Quick Bird Satellite Imagery

In the present study, the nitrogen index was low with 1.32 in the surface soil and 1.02 in the subsurface soil (Table 1). The lower nitrogen content in the 50 year old cultivated soil may be attributed to the congenial atmosphere for leaching losses of nitrogen owing to the sandy texture and intensive irrigation systems practiced in the farm. The data unveils the fact that split application of nitrogenous fertilizers and use of slow release nitrogenous 

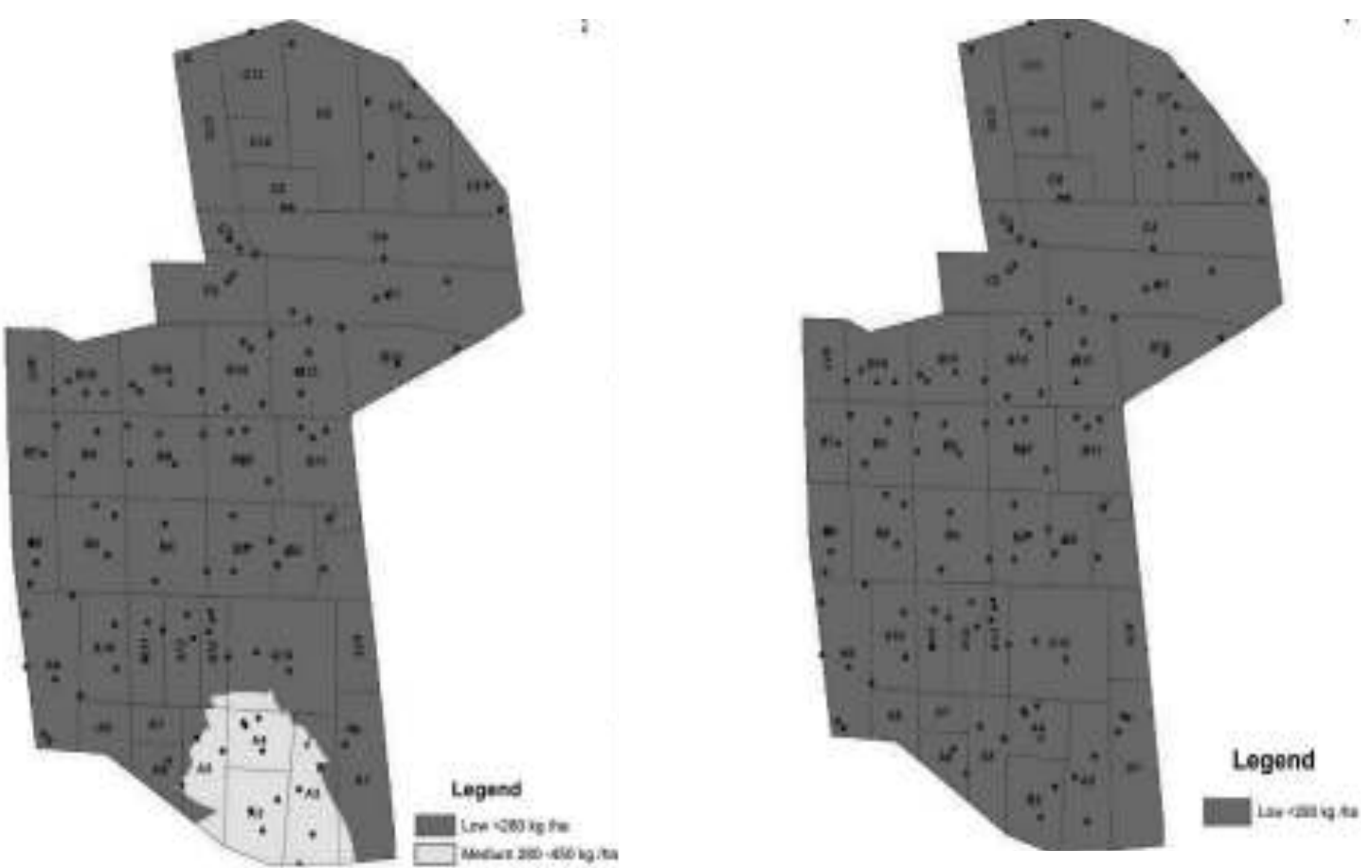

Figure 3. Spatial variability of $\mathrm{KMnO}_{4}-\mathrm{N}\left(\mathrm{kg} \mathrm{ha}^{-1}\right)$ in the surface and subsurface samples of CRS, Aliyar Nagar

fertilizers together with copious application of organic manures is the need of the hour. Due to accelerated decomposition of crop residues in sandy textured soils, maintenance of sufficient organic matter in the farm is a great challenge ahead. Fertilization programme should orient towards increasing the apparent recovery of nitrogen for maximizing crop yields.

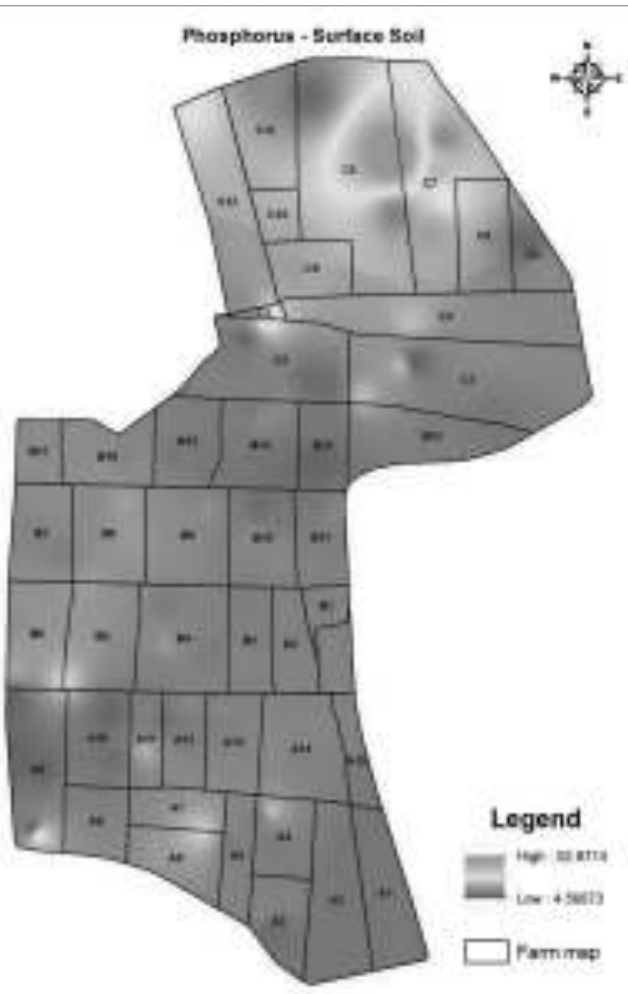

\section{Olsen phosphorus}

The available phosphorus content of the farm soils ranged from 5.3 to $40.1 \mathrm{~kg} \mathrm{ha}^{-1}$ with a mean content of $11.7 \mathrm{~kg} \mathrm{ha}^{-1}$. The general status of Olsen $P$ was almost low to medium in the surface with $43 \%$ of the samples falling in the low category and $57 \%$ in the medium category. In the sub surface, about $50 \%$ fall

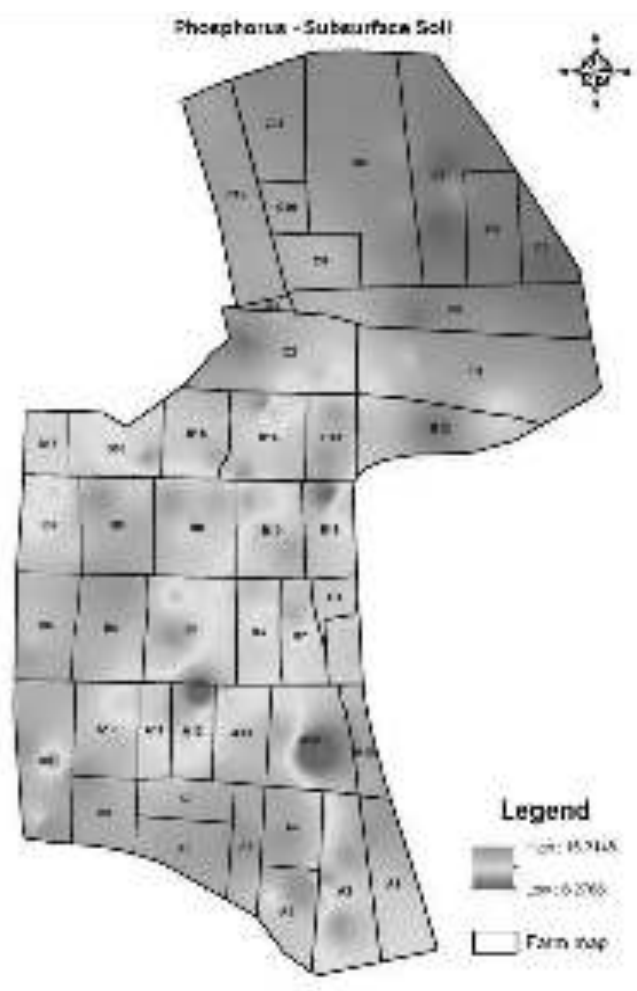

Figure 4. Spatial variability of Olsen $-\mathrm{P}\left(\mathrm{kg} \mathrm{ha}^{-1}\right)$ in the surface and subsurface samples of CRS, Aliyar Nagar 

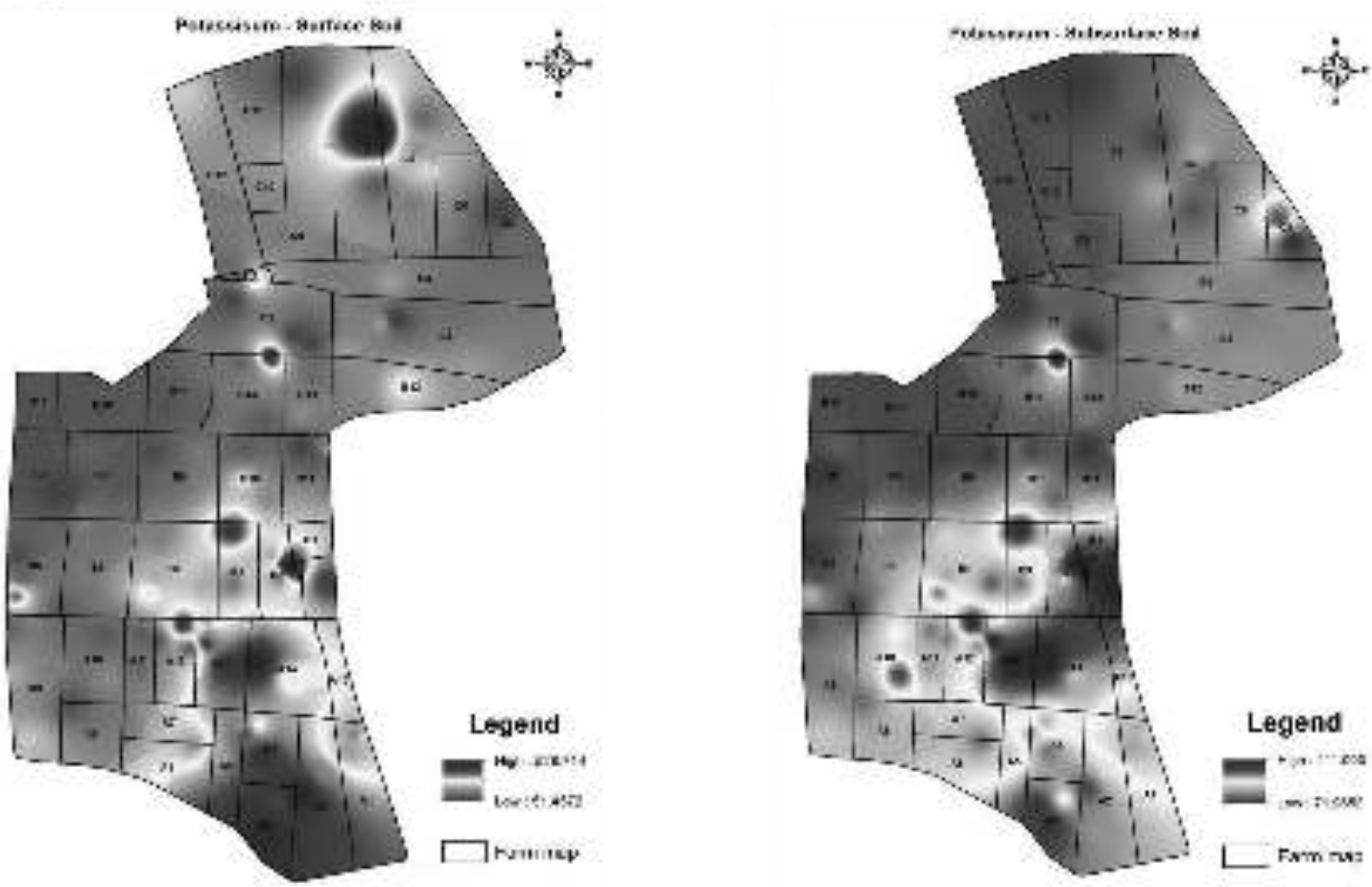

Figure 5. Spatial variability of $1 \mathrm{NNH} 4 \mathrm{O}-\mathrm{Ac}\left(\mathrm{kg} \mathrm{ha}^{-1}\right)$ in the surface and subsurface samples of CRS, Aliyar Nagar

in the low category, $49 \%$ in the medium category and $1 \%$ recorded high status of Olsen- $P$ (Figure 4 ). Phosphorus index in the surface and subsurface soil samples was 1.57 and 1.51 respectively, both representing the low category (Table 1).

Coarse-textured soils generally hold much less phosphate due to the more inert character of sand particles as compared to clay particles. According to Busman et al., 2002, the subsoil of many soils often has a greater capacity to hold phosphate than does the corresponding surface soil. The data collected in the farm paints a caution note about the paucity of organic matter in the system to mineralize phosphorus in the soil. Also that the elevated $\mathrm{CaCO}_{3}$ content in several of the sampling locations would have trapped phosphorus as calcium phosphate preventing it entering into the labile pool. Loading soils with very high levels of phosphate may result in increased phosphate movement to nearby water bodies resulting in environmental hazards. Hence organic manures and biofertilizers are to be included in the nutrition schedule to enhance the available phosphorus status of the coarse textured soils of the farm.

Figure 4. Spatial variability of Olsen - P $(\mathrm{kg}$ $\mathrm{ha}^{-1}$ ) in the surface and subsurface samples of CRS, Aliyar Nagar

\section{Neutral normal ammonium acetate potassium}

Available potassium content in the soil samples was estimated as per Stanford and English, 1949. Of the 258 surface and sub-surface samples, about 88 soil samples were low (34\%), 138 samples were medium (53 \%) and 32 samples (12\%) were high in exchangeable potassium content (Figure 5). Potassium index was medium with 2.27 in the surface soils and 2.24 in the subsurface samples (Table 1).

Table 1. Nutrient index and interpretative groupings of the farm soils of CRS, Aliyar Nagar

\begin{tabular}{lccc}
\hline Parameter & $\mathrm{KMnO}_{4}-\mathrm{N}$ & Olsen - P & $\begin{array}{c}1 \mathrm{NNH} 4 \mathrm{O} \\
\mathrm{Ac}-\mathrm{K}\end{array}$ \\
\hline Minimum $\left(\mathrm{kg} \mathrm{ha}^{-1}\right)$ & 113 & 5.3 & 51.0 \\
Maximum $\left(\mathrm{kg} \mathrm{ha}^{-1}\right)$ & 389 & 40.1 & 530 \\
Mean $\left(\mathrm{kg} \mathrm{ha}^{-1}\right)$ & 233.6 & 11.7 & 166.0 \\
Standard & 39.1 & 3.09 & 85.7 \\
Deviation $\left(\mathrm{kg} \mathrm{ha}^{-1}\right)$ & & & \\
Coefficient of & 16.7 & 26.4 & 51.6 \\
variation & & & \\
Nutrient index & & 1.57 & 2.27 \\
Surface & 1.32 & 1.51 & 2.24 \\
Subsurface & 1.08 & & \\
\hline
\end{tabular}

The soils of the Western Ghats are reported to be poor in potassium fertility. The farm belongs to the region which is highly weathered and rich in kaolinitic clay mineral which has hardly any binding site for potassium (Venkatesan and Murugesan, 2006). The data further draws support from the poor cation exchange capacity of the soils of the farm which is $1-3 \mathrm{cmol}(\mathrm{p}+) \mathrm{kg}^{-1}$ soil. Hence split application of potassic fertilizers and redefining potassium recommendations can alone go a long way in increasing the exchangeable pool of potassium in the sandy textured soils of the farm.

To conclude, nitrogen and phosphorus indices were low irrespective of the depth of sampling whilst potassium index was medium in both the surface 
and subsurface layers of the farm. Sandy texture of the soils of the farm, flood irrigation systems, low water table, paucity of organic matter due to rapid mineralization, poor base exchange status and kaolinitic clay mineral with poor potassium binding sites are the reasons staging nutrient deficiencies. Revisiting fertilizer recommendations for sandy textured soils, building up the organic matter content through residue recycling, split application of $\mathrm{N}$ and $\mathrm{K}$ fertilizers and water saving irrigation systems hold great promise in improving the soil health of the farm.

\section{Acknowledgement}

The authors gratefully acknowledge the efforts of Mr.S.Manoharan, Deputy Director (Agriculture), Department of Remote Sensing and GIS, TNAU, Coimbatore for undertaking detailed survey of the farm and in sharing his rich expertise for drawing valid interpretations.

\section{References}

Gaston, L.A., Locke, M.A., Zablotowicz, R.M. and Reddy, K.N. 2001. Spatial variability of soil properties and weed populations in the Mississippi delta. Soil Sci. Soc. Am. J., 65: 449 - 459.

Havlin, H.L., Beaton, J.D., Tisdale, S. L. and Nelson, W.

L. 2010. Soil Fertility and Fertilizers: An introduction

to nutrient management ( $7^{\text {th }}$ edition). PHI Learning Private Limited, New Delhi.
Ladha, J.K., Pathak, H., Krupnik, T.J., Si, J. and Van Kessel, C. 2005. Efficiency of fertilizer nitrogen in cereal production : retrospect and prospects. Adv. Agron., 87: $85-156$.

Liu, M., Yu, Z., Liu, Y. and Konijn, N.T. 2006. Fertilizer requirements for wheat and maize in China : the QUEFTS approach. Nutr. Cycl Agroecosyst., 74: 245- 258.

Olsen, S. R., Cole, C.V., Watanabe, F.S. and Dean, L.A. 1954. Estimation of available phosphorus in soils by extraction with sodium bicarbonate. U.S. Department of Agriculture, 939.

Rockstrom, J., Barron, J., Brouwer, J., Galle, S. and de Rouw, A. 1999. On-farm spatial and temporal variability of soil and water in pearlmillet cultivation. Soil Sci. Am.J. 63: 1308 - 1319.

Sharma, P.K. 2004. Emerging technologies of remote sensing and GIS for the development of spatial data structure. J. Indian Soc. Soil Sci., 52(4): 384-406.

Stanford, S. and English, 1949. Use of flame photometer in rapid soils tests for potassium and calcium. Agron. J., 41: 446-447.

Subbiah, B.V. and Asija, G.L., 1956. A rapid procedure for the estimation of available nitrogen in soil. Curr. Sci., 25: 259.

Venkatesan,S. and S. Murugesan. 2006. Influence of tea cultivation on soil characteristics with special reference to potassium. Int. J. Soil Science., 1(1): 58-63. 